\title{
Adipose tissue: A natural resource for multipotent mesenchymal stem cells with potential translation to trigerminal layers
}

\author{
Bhaskar Vyas, Atul Shah, Anant Marathe, Ansarullah, Rajni Vyas, Ramesh Bhonde ${ }^{1}$ \\ Samanvaya Trust, Vadodara, Gujarat, ${ }^{1}$ Manipal Institute of Regenerative Medicine, Bengaluru, Karnataka, India
}

Address for correspondence: Dr. Rajni Vyas, Parimal Pratap Road, Raopura, Vadodara - 390 001, Gujarat, India.

E-mail: totalpotentialcells@gmail.com

\section{ABSTRACT}

Background: The article reports basic science research that establishes that adipose tissue (AT)-derived mesenchymal stem cells (MSCs) have a potential to transgerminal translation. Study Design: MSC confirmation was obtained by phenotypic spindle-shaped cells as well as with four positive and three negative markers. The translineage translation of adipose-derived MSCs (ADMSCs) was established. Materials and Methods: The lipoaspirate was subjected to enzymatic digestion with collagenase. Stromal vascular factor (SVF) was isolated. With two passages, pure culture of ADMSCs was obtained. They were translated to all the three germinal layers. Results: AT-derived SVF contains $\sim 30 \%$ MSCs. They are capable of being translated into endoderm, mesoderm and ectoderm. Conclusion: AT is a rich source for MSCs, with immense research possibilities for regeneration and rejuvenation.

\section{KEY WORDS}

Adipose tissue; mesenchymal stem cells; stromal vascular fraction

\section{INTRODUCTION}

esenchymal stem cells (MSCs) are adult non-hematopoietic multipotent stem cells. They have received considerable importance in cellular therapy in degenerative disorders, ${ }^{[1,2]}$ traumatic injuries ${ }^{[3-5]}$ and autoimmune disorders. ${ }^{[6]}$ They have also been tried in metabolic disorders such as diabetes $^{[7,8]}$ due to their multiple modes of action and their transgerminal translation potential. They hone to

\begin{tabular}{|l|l|}
\hline \multicolumn{2}{|c|}{ Access this article online } \\
\hline Quick Response Code: & Website: \\
\hline & www.ijps.org \\
\hline & Dol: \\
\hline
\end{tabular}

the sight of injury or lesion, ${ }^{[9]}$ they are immunonaïveand in addition, they have immunomodulatory action. ${ }^{[10]}$ In this study, we have gathered evidence of trigerminal translation potential of MSCs in in vitro condition in our GMP Class V, Department of Scientific and Industrial Research approved stem cell research laboratory. This will foster newer modalities of cellular treatment of various disorders.

This is an open access journal, and articles are distributed under the terms of the Creative Commons Attribution-NonCommercial-ShareAlike 4.0 License, which allows others to remix, tweak, and build upon the work non-commercially, as long as appropriate credit is given and the new creations are licensed under the identical terms.

For reprints contact: reprints@medknow.com

How to cite this article: Vyas B, Shah A, Marathe A, Ansarullah, Vyas R, Bhonde R. Adipose tissue: A natural resource for multipotent mesenchymal stem cells with potential translation to trigerminal layers. Indian J Plast Surg 2018;51:177-81. 
MSCs are found in varying quantities in the stromal vascular factor (SVF) obtained from different tissues. Adipose tissue (AT) is the richest source for MSCs since SVF obtained therefrom contains approximately $30 \%$ of MSCs. ${ }^{[1]}$ This is likely to open up a vast panorama of various conditions that can be treated with cellular products derived from AT.

\section{MATERIALS AND METHODS}

\section{Selection of subjects for lipoaspiration}

AT was obtained from healthy subjects undergoing liposuction for cosmetic reasons at a planned procedure. Informed consent of the subjects willing to contribute the lipoaspirate for research was taken before procedure. All necessary approvals were taken with Institutional Ethics Committee and Institutional Committee for Stem Cell Research and Therapy.

\section{Lipoaspiration}

Twenty-five subjects who consented underwent lipoaspiration by the plastic surgeon. A patient was given local anaesthesia. 1-2 cm-long incision was made on abdomen ventrolaterally. Lipoaspirate was taken along with the injected ringer solution under vacuum pressure. Five hundred millilitres lipoaspirate was collected for research purpose from each subject. The lipoaspirate was uniform in consistency and was devoid of any clumps.

\section{Isolation and characterisation of stem cells}

Lipoaspirate was washed with phosphate-buffered saline (PBS). Lipoaspirate was then subjected to enzymatic digestion (collagenase type 1,0.75\%) for $2 \mathrm{~h}$ with manual shaking. Finally, the aspirate was centrifuged at $1000 \mathrm{~g}$ to pellet down the mononuclear cells (MNCs). The MNCs obtained are SVF. The pellet was then washed twice with PBS. 2000 cells $/ \mathrm{cm}^{2}$ were seeded in the flask for culturing with Dulbecco's Modified Eagle Medium (DMEM) (HG) and 10\% of foetal bovine serum. The cells, adherent to the surface of flask, were used for characterisation using immunocytochemistry (ICC) and flow cytometry. Flow cytometry results were confirmed at two laboratories. ICC imaging of CD44, CD90, CD105, CD34, CD45 and human leucocyte antigen - -antigen D related (HLA-DR) was done using MSC maker kit (Abcam, USA) following manufacturer's instruction. Similarly, quantification of stem cell population was done with flow cytometry using CD 44, CD 90, CD34 and CD45 markers.

\section{Transdifferentiation into trigerminal cell types}

MSCs obtained were subjected to differentiation into neurogenic cells (ectoderm), chondrocyte (mesoderm) and islet-like cell aggregates ICAs (endoderm). Neural differentiation was done using commercially available differentiation media (Gibco, Thermo scientific, USA) according to manufacturer's instruction. Similarly, chondrocyte differentiation was done using chondrogenesis media (Gibco, Thermo Scientific, USA). ICAs were generated according to Chandra, 2012 protocol, ${ }^{[12]}$ briefly the confirmed adipose-derived MSCs were plated to low attachment plates (HiMedia Laboratories, Mumbai) at density of $10^{6}$ cells $/ \mathrm{cm}^{2}$ in DMEM: F12 until $80 \%$ confluence is achieved. Thereafter, cells were put in serum-free media (SFM) according to the protocol. Differentiation was carried out in three stages; initially, cells were resuspended in SFM-A and were cultured in this media for 2 days. On the $3^{\text {rd }}$ day, cells were shifted to SFM-B media containing taurine. The cell aggregates were cultured in this medium for another 2 days. Finally, cells were further shifted to SFM-C on the $5^{\text {th }}$ day for 14 days. The cell aggregates were fed with fresh SFM-C medium every 2 days in this period.

\section{RESULTS}

Two millilitres of lipoaspirate yielded approximately 1 million SVF cells. SVF was found to contain $\sim 30 \%$ MSCs [Figure 1], The figure also reveals cells positive for CD90(31.18\%), CD34(12.58\%) and CD105(1.37\%). In

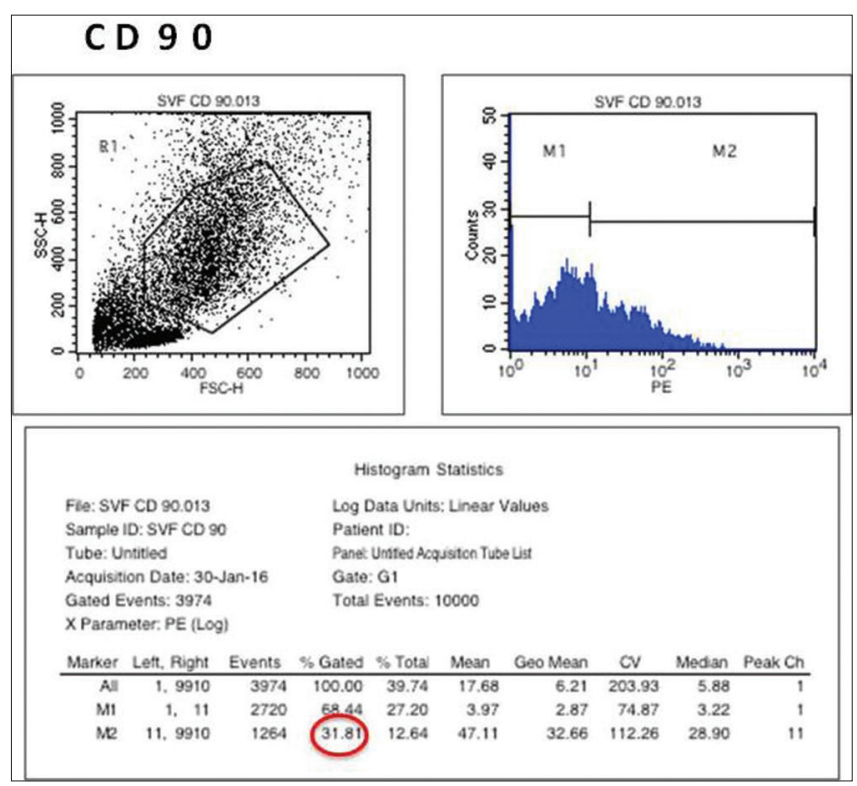

Figure 1: Stromal vascular factor containing CD 90 cells - mesenchymal stem cells 
addition, SVF contained an endothelial precursor cell, T-regulatory cells, macrophages, smooth muscle cells, pericytes and pre-adipocytes.

Cultured and purified MSCs were confirmed with four positive markers CD29, CD44, CD90 and CD105 and were negative for three markers CD34, CD45, CD31 and HLA-DR12. Their translineage translation to mesoderm was confirmed, by evidence for chondrogenesis [Figure 2]. Endodermal translation was confirmed by obtaining insulin-secreting cells [Figure 3]. Ectodermal translation was established with a phenotypic translation to a neuronal-like cell [Figure 4].

\section{DISCUSSION}

The cost of finding a new molecular drug has been steadily increasing from $\$ 1.2$ billion in 2001 to $\sim \$ 3.0$ billion in 2017 (Pfizer company report).

MSCs derived from bone marrow underwent extensive research and application for regeneration. In the present decade, this cell line is being replaced by yet another easily accessed and more abundant source of MSCs - this is AT. This study reflects on a huge potential for plastic surgeons to utilise the skills to extend to a super speciality of regenerative medicine as an autologous source. The safety of MSCs by intra-articular, intramuscular and intravenous route is established. ${ }^{[13]}$ The dosages range from as low as 10 million MSCs ${ }^{[13]}$ to 5 million MSCs $/ \mathrm{kg}$ body weight (BW). ${ }^{[14,15]}$ We have exhibited 3-4 million $/ \mathrm{kg}$ BW SVF cells. ${ }^{[16]}$

The human AT is an abundant source for stromal vascular fraction, containing a cocktail of mesenchymal as well as haemopoiesis, and other cells provide a base for cell therapy. Thus, it has established its place as a plausible source for therapeutic application (PRS 2015).

We have proven the therapeutic application of SVF with platelet-rich plasma for osteoarthritis of the knee. ${ }^{[16]}$ Osteoarthritis anywhere else in the body has similar pathogenesis and morbid anatomy with only minor variations; therefore, we believe that SVF will have therapeutic applications there also. SVF with enrichment of platelets can also be applied to avascular necrosis of femur ${ }^{[17]}$ and even to delayed healing at fracture sites. ${ }^{[18]}$ A further research possibility exists for application of SVF in rheumatoid joints as well.

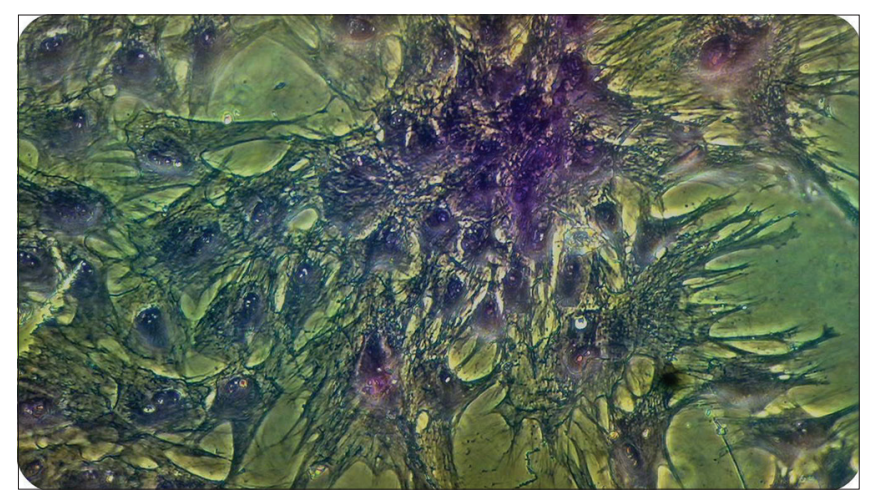

Figure 2: Adipose-derived mesenchymal stem cells translated to chondrogenesis

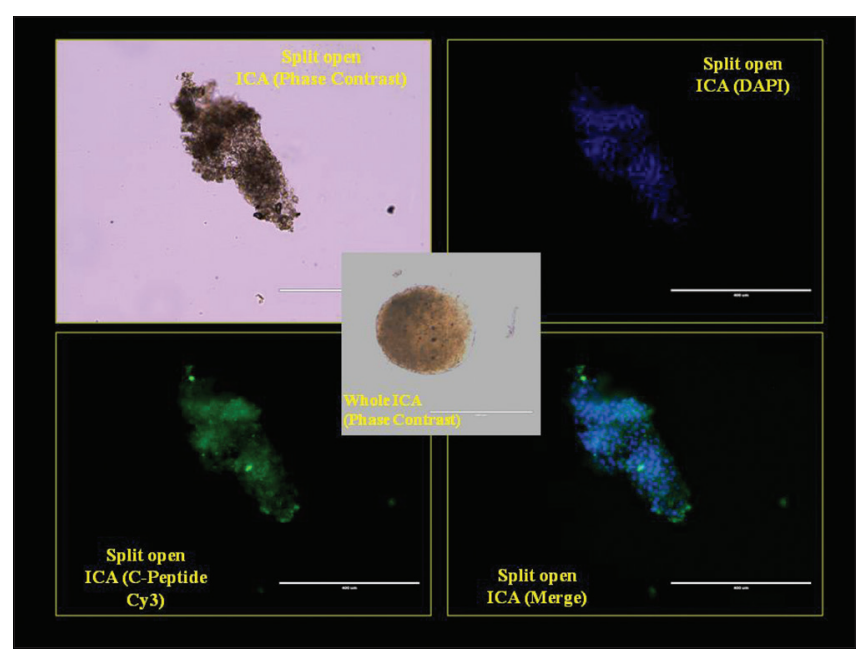

Figure 3: Adipose-derived mesenchymal stem cells translated to islet-like cell aggregates

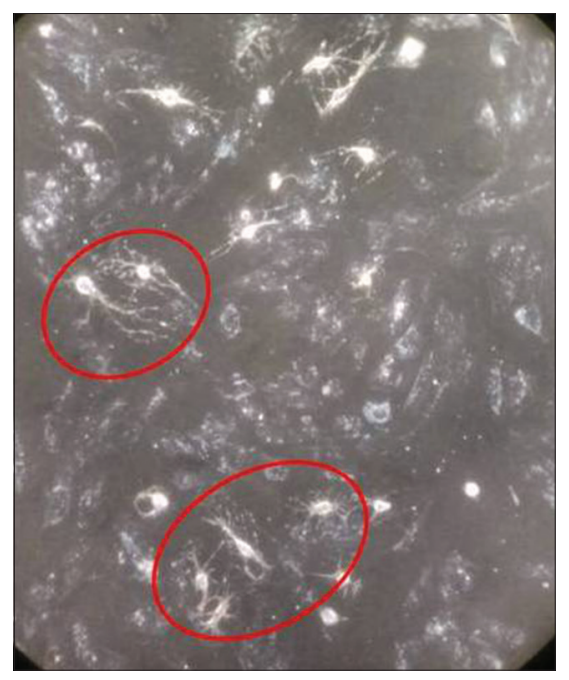

Figure 4: Adipose-derived mesenchymal stem cells translated to neuronal-like cells

Besides this, researchers have exhibited SVF to treat extensiveburns, ${ }^{[19]}$ diabeticfoot, ${ }^{[20 \mid}$ breastaugmentation, ${ }^{[21]}$ nerve regeneration ${ }^{[22]}$ and wound healing, ${ }^{[23]}$ diabetes $^{[24]}$ and ischemic heart failure. ${ }^{[25]}$

Indian Journal of Plastic Surgery Volume 51 Issue 2 May-August 2018 
MSC translation to insulin-producing cells has a potential for application for type I and II diabetes. ${ }^{[12]}$ We have proven glucose-lowering activity of SVF in seven diabetic patients. ${ }^{[26]}$ MSCs have research potential for application to several neurological disorders that may range from children suffering from cerebral palsy ${ }^{[27]}$ to adults suffering from syringomyelia, ${ }^{[28]}$ Parkinson's disease, ${ }^{[29]}$ Alzheimer's disease ${ }^{[30]}$ etc.

\section{CONCLUSION}

The study adds the evidence for translineage translation of MSCs obtained from AT to existing literature. This opens up a wide panorama for research in therapeutic applications for unmatched challenges. The study also puts a product in the palm of the plastic surgeon available at the doorstep of the operating room.

\section{Acknowledgement}

Dr. Ramesh Bhonde, the then dean of Manipal Institute of Regenerative Medicine, Bangalore, now the research director at D. Y. Patil, Medical College, Pune, provided mentorship. Dr. Prof. (late) Bharat Chattoo, Head Genomic Research Centre, MSU Vadodara, provided the facility for confocal microscopic studies. Toprani Advance Laboratory systems facilitated with flow cytometry studies. We are grateful to them.

\section{Financial support and sponsorship}

The research was partly funded through a SBIRI grant by DBT, Government of India.

\section{Conflicts of interest}

There are no conflicts of interest.

\section{REFERENCES}

1. Orozco L, Munar A, Soler R, Alberca M, Soler F, Huguet M, et al. Treatment of knee osteoarthritis with autologous mesenchymal stem cells: A pilot study. Transplantation 2013;95:1535-41.

2. Jang WG, Kim EJ, Park KG, Park YB, Choi HS, Kim HJ, et al. Glucocorticoid receptor mediated repression of human insulin gene expression is regulated by PGC-1alpha. Biochem Biophys Res Commun 2007;352:716-21.

3. Mackay-Sim A, Féron F, Cochrane J, Bassingthwaighte L, Bayliss C, Davies W, et al. Autologous olfactory ensheathing cell transplantation in human paraplegia: A 3-year clinical trial. Brain 2008;131:2376-86.

4. Park JH, Kim DY, Sung IY, Choi GH, Jeon MH, Kim KK, et al. Long-term results of spinal cord injury therapy using mesenchymal stem cells derived from bone marrow in humans. Neurosurgery 2012;70:1238-47.

5. et al.Gazdic M, Volarevic V, Harrell CR, Fellabaum C, Jovicic N, Arsenijevic N, et al. Stem cells therapy for spinal cord injury. Int
J Mol Sci 2018;19. pii: E1039.

6. Le Blanc K, Rasmusson I, Sundberg B, Götherström C, Hassan M, Uzunel $\mathrm{M}$, et al. Treatment of severe acute graft-versus-host disease with third party haploidentical mesenchymal stem cells. Lancet 2004;363:1439-41.

7. Wu H, Mahato RI. Mesenchymal stem cell-based therapy for type 1 diabetes. Discov Med 2014;17:139-43.

8. Zang L, Hao H, Liu J, Li Y, Han W, Mu Y, et al. Mesenchymal stem cell therapy in type 2 diabetes mellitus. Diabetol Metab Syndr 2017;9:36.

9. Rustad KC, Gurtner GC. Mesenchymal stem cells home to sites of injury and inflammation. Adv Wound Care (New Rochelle) 2012;1:147-52.

10. Nauta AJ and Fibbe WE. Immunomodulatory properties of mesenchymal stromal cells. Blood 2007;110:3499-506.

11. BunnellBA, FlaatM, Gagliardi C, PatelB, Ripoll C.Adipose-derived stem cells: Isolation, expansion and differentiation. Methods 2008;45:115-20.

12. Chandra V, Swetha G, Muthyala S, Jaiswal AK, Bellare JR, Nair PD, et al. Islet-like cell aggregates generated from human adipose tissue derived stem cells ameliorate experimental diabetes in mice. PLoS One 2011;6:e20615.

13. Strauer BE, Brehm M, Zeus $T$, Gattermann N, Hernandez A, Sorg RV, et al. Intracoronary, human autologous stem cell transplantation for myocardial regeneration following myocardial infarction. Dtsch Med Wochenschr 2001;126:932-8.

14. Chen SL, Fang WW, Ye F, Liu YH, Qian J, Shan SJ, et al. Effect on left ventricular function of intracoronary transplantation of autologous bone marrow mesenchymal stem cell in patients with acute myocardial infarction. Am J Cardiol 2004;94:92-5.

15. Hare JM, Traverse JH, Henry TD, Dib N, Strumpf RK, Schulman SP, et al. A randomized, double-blind, placebo-controlled, dose-escalation study of intravenous adult human mesenchymal stem cells (prochymal) after acute myocardial infarction. J Am Coll Cardiol 2009;54:2277-86.

16. Kshatriya P, Marathe A, Thadani J, Vakodikar S, Vyas R, Bhonde R. Innovation of a novel therapeutic modality for treatment of osteoarthritis of knee with autologous adipose derived stromal vascular fraction. IP J Indian Orthop Rheumatol Assoc 2017;3:59-66.

17. Pak J, Lee JH, Jeon JH, Lee SH. Complete resolution of avascular necrosis of the human femoral head treated with adipose tissue-derived stem cells and platelet-rich plasma. J Int Med Res 2014;42:1353-62.

18. Valencia Mora M, Ruiz Ibán MA, Díaz Heredia J, Barco Laakso R, Cuéllar R, García Arranz M, et al. Stem cell therapy in the management of shoulder rotator cuff disorders. World J Stem Cells 2015;7:691-9.

19. Atalay $S$, CoruhA, DenizK. Stromal vascular fraction improves deep partial thickness burn wound healing. Burns 2014;40:1375-83.

20. Han SK, Kim HR, Kim WK. The treatment of diabetic foot ulcers with uncultured, processed lipoaspirate cells: A pilot study. Wound Repair Regen 2010;18:342-8.

21. Yoshimura K, Sato K, Aoi N, Kurita M, Hirohi T, Harii K, et al. Cell-assisted lipotransfer for cosmetic breast augmentation: Supportive use of adipose-derived stem/stromal cells. Aesthetic Plast Surg 2008;32:48-55.

22. di Summa PG, Kingham PJ, Raffoul W, Wiberg M, Terenghi G, Kalbermatten DF, et al. Adipose-derived stem cells enhance peripheral nerve regeneration. J Plast Reconstr Aesthet Surg 2010;63:1544-52.

23. Cianfarani F, Toietta G, Di Rocco G, Cesareo E, Zambruno G, Odorisio $\mathrm{T}$, et al. Diabetes impairs adipose tissue-derived stem cell function and efficiency in promoting wound healing. Wound 
Repair Regen 2013;21:545-53.

24. Jarajapu YP, Grant MB. The promise of cell-based therapies for diabetic complications: Challenges and solutions. Circ Res 2010;106:854-69.

25. You HJ, Han SK. Cell therapy for wound healing. J Korean Med Sci 2014;29:311-9.

26. Vyas B, Vyas R, Ansarullah, Marathe A, Thadani J, Kshatriya P, et al. Therapeutic application of autologous adipose derived mesenchymal stem cells and islet like cell aggregates derived from them in type 1 and 2 diabetes mellitus - A proof of concept study. J Stem Cell Res Dev Ther 2016;3: 008.

27. Zhang C, Huang L, Gu J, Zhou X. Therapy for cerebral palsy by human umbilical cord blood mesenchymal stem cells transplantation combined with basic rehabilitation treatment: A Case report. Glob Pediatr Health 2015;2:2333794x15574091.

28. Vaquero J, Hassan R, Fernández C, Rodríguez-Boto G, Zurita M. Cell therapy as a new approach to the treatment of posttraumatic syringomyelia. World Neurosurg 2017;107:1047.e5-1047.e8.

29. Kitada M, Dezawa M. Parkinson's disease and mesenchymal stem cells: Potential for cell-based therapy. Parkinsons Dis 2012;2012:873706.

30. Turgeman $G$. The therapeutic potential of mesenchymal stem cells in Alzheimer's disease: Converging mechanisms. Neural Regen Res 2015;10:698-9. 